\title{
Expression of miR-625 and Fas in cervical vertebral cartilage endplate
}

\author{
BEILEI ZHAN ${ }^{1}$, YAN ZHAN ${ }^{2}$, WEI WANG $^{1}$, YUNZHONG ZHAN $^{1}$ and BINGSHENG LIU ${ }^{1}$ \\ Departments of ${ }^{1}$ Orthopedics and ${ }^{2}$ Science and Education, Quzhou People's Hospital, Quzhou, Zhejiang 324000, P.R. China
}

Received September 18, 2015; Accepted January 1, 2017

DOI: 10.3892/etm.2017.5403

\begin{abstract}
The aim of the present study was to assess miR-625 and Fas expression in normal and degenerative cervical cartilage endplate (CEP) tissues. Following biof-informatics analysis, the Fas gene was predicted to be one of the targets of miR-625. Quantitative PCR (qPCR) and western blotting were used to detect miR-625 and Fas expression in normal and degenerative CEP. A luciferase reporter assay was used to identify whether miR-625 could directly target the 3 ' untranslated region (3'-UTR) of Fas. Lentiviral overexpression and/or inhibition vectors of miR-625 (pre-miR-625)/antigomiR-625 were constructed to determine whether overexpression or inhibition of miR-625 could affect Fas and B-cell lymphoma 2 (Bcl-2) expression in cartilaginous endplate cells (CECs) and tissues. qPCR analysis demonstrated that miR-625 expression in degenerative CEP was significantly lower than in normal CEP tissue, while the production of Fas in degenerated CEP was significantly higher. Results from western blotting also showed a significant increase in Fas expression in degenerative CEP. miR-625 can bind directly to the 3'-UTR of the Fas gene. However, this inhibition was attenuated by a target mutation in the miR-625-binding site of the 3'-UTR of Fas mRNA. In addition, following transfection of CECs with pre-miR-625 and antigomiR-625, expression of Fas significantly decreased and increased, respectively, and Bcl-2 expression was upregulated and downregulated, respectively. Upregulation of miR-625 can inhibit Fas expression and further affect Bcl-2 expression in CEP degeneration, suggesting that miR-625-mediated inhibition of the Fas gene is important in cervical degeneration.
\end{abstract}

\section{Introduction}

Cervical disc disease is a common disease, of which the prevalence is rising and the age of onset is decreasing $(1,2)$.

Correspondence to: Dr Yan Zhan, Department of Science and Education, Quzhou People's Hospital, 2 ZhonglouDi, Kecheng, Quzhou, Zhejiang 324000, P.R. China

E-mail:rrb333@163.com

Key words: endplate degeneration, miR-625, Fas
Cervical disc disease is characterized by degeneration in the neck, bones, cartilage and ligaments, which can stimulate the peripheral spinal cord, nerve roots, vascular, soft tissues and the sympathetic nerve. This degeneration causes pain in different areas of the body, leading to serious health problems (3). It has been suggested that cervical disc disease is primarily caused by the breakdown of intervertebral discs (4). Intervertebral discs consist of a nucleus, annulus and endplate. Pathological changes in the intervertebral disc primarily include calcification of cervical cartilage endplate (CEP), abnormal annulus fibrosis and proteoglycan, and loss of water in the nucleus pulposus (5).

Vertebral CEP, a thin layer of hyaline cartilage located between the upper and lower surfaces of the vertebra body, is an important part of the intervertebral disc, which is composed of cartilage cells and extracellular matrix. Its degeneration is accompanied by a loss of nutrients in the extracellular matrix, which is considered to contribute to the initiation and development of degenerative disc disease (6). As the largest avascular structure of the body, CEP functions mechanically as a shock absorber and is also an important gateway allowing nutrients and metabolites to pass freely between the avascular nucleus pulposus and vertebral body (7). CEP also serves an important role in the growth of the vertebral body, and is important in facilitating the normal physiological function of the spine $(5,8)$. It also serves as a natural barrier to prevent damaging substances, such as matrix metalloproteinases, inflammatory cytokines and immune molecules, from entering the nucleus $(8,9)$. A number of studies have indicated that the initiation of disc degeneration may be due to the degeneration, dysfunction and calcification of endplates $(10,11)$. CEP is almost totally reliant on the orderly expression of genes to maintain its normal development and function; therefore, any minor errors in genetic pathways can lead to severe endplate degeneration (12-14).

In recent years, microRNAs (miRs), which are small RNAs that regulate gene expression at the post-transcriptional level, have been an important focus of various studies. miRs are a class of highly conserved, non-coding RNA molecules that are 21-25 bases long and participate in gene regulation by pairing with a non-coding region of the target mRNA molecule. This leads to changes in mRNA stability and translation performance. miRs also serve crucial roles in cell proliferation, apoptosis and differentiation (15). Bioinformatics research predicts that around a third of mRNA 
is regulated by miRs in humans (16). Furthermore, a number of studies have demonstrated that miR is not only involved in the regulation of cartilage development, but also serves pivotal roles in the pathogenesis of the nucleus pulposus degeneration and arthritis $(17,18)$. However, it remains unknown whether miR is associated with the molecular mechanism of CEP degeneration.

Fas, also known as apoptosis antigen 1 or cluster of differentiation 95, is located on the cell membrane and is a type I membrane receptor protein consisting of extracellular, transmembrane and cytoplasmic domains (19). An amino acid sequence of the cytoplasmic domain, Fas-associated death domain (FADD), is highly homologous to the tumor necrosis factor receptor, which in turn interacts with the death domain (20). The Fas system has been extensively studied in apoptosis. The extracellular portion of the Fas can specifically bind to the anti-Fas monoclonal antibody or Fas ligand (FasL), mediating apoptosis through the death domain or death signal transduction pathway (21). Most research so far has focused on endplate apoptosis in intervertebral disc degeneration with aging. Ariga et al (10) demonstrated that CEP degenerative mice have apoptotic cells that increase with age and external pressures, including excessive exercise and overload, leading to a decline of cartilaginous endplate cells (CEC). The higher the rate of apoptosis, the more quickly CEP disappeared (22). Although there are a few studies that reveal abnormal expression profiles of miRNAs in degenerative CEP, the specific molecular mechanisms involved in the disease process remain unclear (23-25).

In the present study, the association between miR-625 and Fas expression in human cervical degenerative disc endplates was investigated, with the aim of identifying the mechanism of miRNAs in the development of cervical disease.

\section{Materials and methods}

Patients. A total of 30 patients were enrolled from Quzhou People's Hospital (Quzhou, China) and divided into two groups as described below. The case group consisted of 15 patients with cervical disease, including 8 males and 7 females (mean age, 52.6 years; age range, 46-62 years). All patients were diagnosed with cervical disease by X-ray, computed tomography and magnetic resonance imaging (MRI) tests. The control group was composed of 15 patients with cervical burst fracture and vertebral reconstruction surgery due to trauma, and included 9 males and 6 females (mean age, 47.2 years; age range, $38-58$ years). Patients with disc degeneration detected by MRI test, tuberculosis, cancer, diabetes, genetic and metabolic diseases and congenital malformation were excluded from the current study. Tissue samples were isolated during surgery and were immediately frozen with liquid nitrogen and stored at $-80^{\circ} \mathrm{C}$. Use of the stored human specimens in the present study was approved by the Ethical Committee of Quzhou People's Hospital and informed consent was obtained from all patients.

Reagents. TRIzol ${ }^{\circledR}$ reagent, Lipofectamine ${ }^{\mathrm{TM}} 2000$ reagent, radioimmunoprecipitation assay buffer (RIPA), lentiviral vector encoding pre-miR-625 and a scrambled sequence for control were all purchased from Invitrogen (Thermo Fisher Scientific, Inc., Waltham, MA, USA). Rabbit anti-human
Fas/B-cell lymphoma 2 (Bcl-2) polyclonal antibody was obtained from Abcam (Cambridge, MA, USA), PrimeScript RT Reagent kit and SYBR ${ }^{\circledR}$ PrimeScript $^{\mathrm{TM}}$ miRNA RT-PCR kit were purchased from Takara Biotechnology Co., Ltd. (Dalian, China). mRNA SYBR Green RT-PCR reagent was purchased from Kapa Biosystems, Inc., (Wilmington, MA, USA), enhanced chemiluminescence (ECL) kit was purchased from Pierce Biotechnology (Thermo Fisher Scientific, Inc.) and QuikChange XL site-directed mutagenesis kit was from Stratagene (Agilent Technologies, Inc., Santa Clara, CA, USA).

CEP cell culture. Degenerative cervical CEP samples were obtained from clinical specimens [Modic type 1 or 2 (26), isolated in lumbar fusion surgery] and were used for cell culture. Tissues were separated by a dissecting microscope to remove cross-contamination between the tissues and the surrounding ligaments, thus obtaining CEP tissue alone. Following removal of the endplate tissue, tissues were washed repeatedly with $0.1 \mathrm{M}$ phosphate-buffered saline containing $100 \mathrm{U} / \mathrm{ml}$ penicillin and streptomycin to remove the blood on the surface of the endplate. Subsequently, tissues were digested with $0.2 \%$ type II collagenase (HyClone; GE Healthcare Life Sciences, Logan, UT, USA) and Dulbecco's modified Eagle medium (DMEM)/F12 (HyClone; GE Healthcare Life Sciences) for $6 \mathrm{~h}$ and then filtered through a mesh with a pore size of $100 \mu \mathrm{m}$. The filtrate was centrifuged at $350 \mathrm{x} \mathrm{g}$ for $10 \mathrm{~min}$ at room temperature. Supernatant was removed and DMEM/F12 medium containing $10 \%$ fetal bovine serum (HyClone; GE Healthcare Life Sciences) was added to re-suspend the cells. In total, $2 \times 10^{6}$ cells could be harvested from each specimen.

The total number of viable and nonviable cells was counted under an inverted microscope (Olympus BX50; Olympus Corp., Tokyo, Japan) with the help of a haemocytometer and the trypan blue method (Beijing Solarbio Science and Technology Co., Ltd., Beijing, China) was used to determine the number of viable cells present in the cell suspension. Cells were cultured in an incubator containing $5 \% \mathrm{CO}_{2}$ at $37^{\circ} \mathrm{C}$ and observed under an inverted light microscope. Media were changed every 2-3 days until the culture flask bottom was completely covered.

RNA extraction and reverse transcription. CEP tissues (100 mg) were weighed, ground to a powder in liquid nitrogen and then placed in a centrifuge tube with $1 \mathrm{ml}$ TRIzol reagent for lysis. Total RNA was isolated using the phenol-chloroform method (27), and RNA quality was assessed by electrophoresis and the UV absorption ratio 260/280 using a UV spectrophotometer. A total of $1 \mu \mathrm{g}$ total RNA was used in the reverse transcription reaction to obtain cDNA and stored at $-20^{\circ} \mathrm{C}$. Reverse transcription of miRNA in the samples was performed using the PolyA tailing method. Briefly, $6 \mu \mathrm{l}$ miRNA was added in ice-cold RNase-free eppendorf (EP) tubes and the following were gently mixed in the EP tubes: $10 \mu 12 \mathrm{X}$ miRNA reaction buffer mix, $2 \mu 10.1 \%$ bovine serum albumin (Beyotime Institute of Biotechnology, Haimen, China) and $2 \mu \mathrm{l}$ miRNA PrimeScript RT Enzyme mix (Takara Biotechnology Co., Ltd.). Total final volume was made up to $20 \mu \mathrm{l}$ with double distilled $\mathrm{H}_{2} \mathrm{O}$. The miRNA was treated with cDNAse and the reverse transcription step was performed as follows: PolyA tailing and reverse transcription reaction were 
performed at $37^{\circ} \mathrm{C}$ for $60 \mathrm{~min}$ and $80 \mu \mathrm{l}$ RNAase-free $\mathrm{H}_{2} \mathrm{O}$ was then added to the RT reaction. Finally, quantitative polymerase chain reaction (qPCR) was performed with $2 \mu \mathrm{l}$ product.

Bioinformatics analysis. The miRNA binding sites on the 3'-untranslated (UTR) region of Fas mRNA were predicted using TargetScan (www.targetscan.org).

pFL-Fas 3'-UTR expression vector construction. The potential target sequences for miR-625 in the 3'-UTR of Fas mRNA (Gen-Bank Accession No. NM_000043) were amplified and cloned into pGL3-control reporter plasmids (Promega Corporation, Madison, WI, USA) between the EcoRI and HindIII restriction sites. The stop codon of firefly luciferase was inserted using the same method.

Luciferase reporter gene analysis. Transient co-transfections of $0.8 \mu \mathrm{g}$ pFL-Fas 3'-UTR plasmid, $100 \mathrm{nM}$ miR-625 mimics/miR-control (Ambion; Thermo Fisher Scientific, Inc.) and $0.04 \mu \mathrm{g}$ thymidine kinase promoter-Renilla luciferase reporter plasmid (pRL-TK) were conducted in HEK293 cells (American Type Culture Collection, Manassas, VA, USA) using Lipofectamine 2000 following the manufacturer's instructions. Firefly and Renilla luciferase activities were measured using the Dual-Luciferase Reporter Assay kit (cat. no. E1910; Promega Corporation) according to manufacturer's instructions $48 \mathrm{~h}$ following transfection. pRL-TK is commonly used as a normalization control for transfection efficiency to confirm the inhibition of Fas 3'UTR expression by miR-625. The assay was repeated at least 3 times independently. In order to further explore the role of miR-625 on Fas 3'-UTRs, the QuikChange XL site-directed mutagenesis kit (Stratagene; Agilent Technologies, Inc.) was employed to generate point mutations in the 3'-UTR of the Fas gene of miR-625 binding sites and each mutation contained four sequential bases.

Overexpression or inhibition of $\mathrm{miR}-625$ in CECs. Green fluorescent protein, lentiviral expression vector of pre-miR-625 and the control scrambled oligonucleotides were purchased from Invitrogen (Thermo Fisher Scientific, Inc.). CECs were cultured in each well $\left(1.5 \times 10^{5} /\right.$ well) of a 24 -well culture plate in $250 \mu \mathrm{l}$ DMEM/F12 supplemented with 10\% FBS. Transfected cells were subsequently infected with virus at a multiplicity of infection of 10 , incubated at $37^{\circ} \mathrm{C}$ for $5 \mathrm{~h}$, and observed under an inverted microscope (Olympus Corp.) to confirm successful transfection. To further determine the regulation of miR-625 to Fas in CECs, transient transfection of antigomiR-625 and negative control were preformed in CECs according to the aforementioned method.

qPCR of miR-625 and Fas $m R N A$. The SYBR ${ }^{\circledR}$ PrimeScript miRNA RT-PCR kit was employed using small nuclear RNAs (U6) as an internal reference. The primer sequence for miR-625 was 5'-CCAGGGGGAAAGTTCTATAGTCC-3'. The PCR system $(20 \mu \mathrm{l})$ was as follows: $12.5 \mu \mathrm{l}$ SYBR EX Taq-Mix, $2 \mu \mathrm{l}$ cDNA, $1 \mu \mathrm{l}$ PCR forward primer and $1 \mu \mathrm{l}$ Uni-miR RT-qPCR primer with $8.5 \mu \mathrm{l}$ of $0.1 \%$ diethyl pyrocarbonate (DEPC) $-\mathrm{H}_{2} \mathrm{O}$ added to $25 \mu \mathrm{l}$. Each sample was performed in triplicate. The relative expression levels of miR-625 were calculated using the $2^{-\Delta \Delta \mathrm{Cq}}$ method (28).
To determine the mRNA expression level of Fas in tissues and CECs, the SYBR Green qRT-PCR reagent was employed and glyceraldehyde 3-phosphate dehydrogenase (GAPDH) was used as an internal reference. The mRNA was reverse transcribed into cDNA using a PrimeScript RT reagent Kit with gDNA Eraser (cat. no. RR047Q; Takara Biotechnology Co., Ltd). The primers for Fas mRNA were synthesized by Sangon Biotech Co., Ltd. (Shanghai, China). Primer sequences were as follows: FAS, forward 5'-GAGCTCGTCTCTGATCTCGC-3', and reverse 5'-AAAGAGCTTCCCCAACTCCG-3'; GAPDH, forward 5'AAGGTGAAGGTCGGAGTCA3' and reverse: 5'GGAAGATGGTGATGGGATTT3'. The PCR system $(20 \mu \mathrm{l})$ was as follows: $10 \mu \mathrm{l} \mathrm{SYBR} \mathrm{EX} \mathrm{Taq-Mix,} 1 \mu \mathrm{l}$ cDNA, $0.5 \mu 1$ primer $1,0.5 \mu \mathrm{l}$ primer 2 , with $8 \mu \mathrm{l}$ of $0.1 \%$ DEPC- $\mathrm{H}_{2} \mathrm{O}$ added to $20 \mu \mathrm{l}$. Each sample was performed in triplicate. The PCR conditions consisted of denaturation at $95^{\circ} \mathrm{C}$ for $10 \mathrm{~min}, 95^{\circ} \mathrm{C}$ for $1 \mathrm{~min}, 60^{\circ} \mathrm{C}$ for $40 \mathrm{sec}$ and $72^{\circ} \mathrm{C}$ for $30 \mathrm{sec}$, for a total of 40 cycles. A final extension was performed at $72^{\circ} \mathrm{C}$ for $1 \mathrm{~min}$. Finally, the relative expression levels of Fas were calculated using the $2^{-\Delta \Delta \mathrm{Cq}}$ method (19).

Western blot analysis. A total of $100 \mu \mathrm{g}$ cervical tissue was weighed, ground to a power in liquid nitrogen and then placed in a centrifuge tube with $600 \mu \mathrm{l}$ ice-cold RIPA reagent (50 mM Tris-base, $1 \mathrm{mM}$ EDTA, $150 \mathrm{mM} \mathrm{NaCl,} \mathrm{0.1 \%} \mathrm{SDS,}$ $1 \%$ TritonX-100 and $1 \%$ sodium deoxycholate) for $50 \mathrm{~min}$. Subsequently, the sample was centrifuged at $12,000 \mathrm{x} \mathrm{g}$ for $5 \mathrm{~min}$ at $4^{\circ} \mathrm{C}$ to remove precipitates and the supernatant was used as the total protein. Protein concentration was measured using the bicinchoninic acid protein assay reagent kit (cat. no. 23225; Thermo Fisher Scientific, Inc.).

To obtain the total protein from CEC cells, the cells were collected and lysed with the ice-cold RIPA lysis buffer and the protein extraction steps using the aforementioned procedure. A total of $50 \mu \mathrm{g}$ total protein were mixed with $2 \mathrm{X}$ loading buffer and were boiled for $5 \mathrm{~min}$. In total, $5 \mu \mathrm{g}$ protein samples from CEC cells and cervical tissues were separated by $12 \%$ SDS-PAGE at $100 \mathrm{~V}$, and then transferred onto a polyvinylidene difluoride membrane at $300 \mathrm{~mA}$, and $4^{\circ} \mathrm{C}$ for $1.5 \mathrm{~h}$. The membrane was then blocked with $50 \mathrm{~g} / \mathrm{l}$ fat-free milk at room temperature for $1 \mathrm{~h}$, and incubated with anti-Fas primary antibody (1:800; Abcam, Cambridge, UK; cat. no. ab82419), anti-Bcl-2 primary antibody (1:1,000; Abcam; cat. no. ab32124) and anti-GAPDH primary antibody (1:1,000; Abcam; cat. no. ab9485), respectively, at $4^{\circ} \mathrm{C}$ overnight. The membrane was washed 3 times for 15 min each time with phosphate-buffered saline and Tween-20 (PBST) and the membrane was then incubated with goat anti-rabbit secondary antibody (1:1,000; Abcam; cat. no. ab6721) at room temperature for $1 \mathrm{~h}$. The membrane was then washed 3 times for 15 min each time with PBST. Finally, the membrane was developed using an ECL kit and visualized by exposure on films (Merck KGaA, Darmstadt, Germany). Images were captured and quantified by Image lab software 4.0 (Bio-Rad Laboratories, Inc., Hercules, CA, USA). The relative content of the objective protein was represented by the ratio of the objective protein gray value and the gray value of GAPDH.

Statistical analysis. Data were recorded and statistically analyzed using Microsoft ${ }^{\circledR}$ ExcelXP $^{\circledR}$ and SPSS for Windows ${ }^{\circledR}$ 
version 13.0.1 (SPSS, Inc., Chicago, IL, USA). Statistical differences were detected using the Student's t test. Results with a two-sided $\mathrm{P} \leq 0.05$ were considered to indicate a statistically significant difference.

\section{Results}

Fas mRNA levels are increased in CEP tissue. In order to determine the Fas mRNA levels in the CEP tissue samples of controls and patients, qPCR was performed. Levels of Fas mRNA were significantly higher ( 1.7 fold) in degenerative cervical CEP tissues compared with normal CEP tissues $(\mathrm{P}<0.05$; Fig. 1). These results suggest a role for Fas in CEP degeneration.

Fas protein expression is increased in CEP tissue. To further clarify the expression of Fas in the CEP tissue of controls and patients, Fas protein expression was measured using western blot analysis. Fas protein expression was significantly higher in degenerative cervical CEP tissues than in normal CEP tissues ( $\mathrm{P}<0.05$; Fig. 2 ), which is consistent with the expression of Fas at the mRNA level.

Fas is a potential target of miR-625. In order to identify the effect of miR-625 on gene regulation in CEP tissue, TargetScan was used to predict the target gene of miR-625. Fas was selected as the candidate target gene of miR-625 and the binding site was shown to be on the sequential area of 8-base pairs of the Fas 3'UTR (Fig. 3).

miR-625 expression in CEP tissue is lower than in healthy tissue. To determine miR-625 expression in the CEP tissue of patients and controls, qPCR was performed. It was determined that miR-625 expression is significantly lower in degenerative CEP than normal CEP tissue ( $\mathrm{P}<0.05$; Fig. 4).

Dual-luciferase reporter assay. To evaluate the influence of miR-625 on target gene activation, a dual-luciferase reporter assay was used, showing that miR-625 decreased luciferase activity significantly by co-transfection of a mixture of pRL-TK vector and miR-625 mimics together with pFL-Fas 3'-UTR plasmid in cells, compared with the negative control $(\mathrm{P}<0.05$; Fig. 5A). However, mutation of Fas mRNA did not decrease luciferase activity significantly in cells co-transfected with the mutation pFL-Fas 3'-UTR and pRL-TK together with mimics, in comparison to cells transfected with the negative control ( $\mathrm{P}>0.05$; Fig. 5B).

Role of miR-625 on Fas protein expression and its inhibition of the Bcl-2 gene. To ascertain if miR-625 regulates Fas protein, CECs were transfected with pre-miR-625. Upregulation of miR-625 expression significantly reduced the expression of Fas compared with the negative control $(\mathrm{P}<0.05$; Fig. 6A). To further analyze the association between miR-625 and Fas expression in CECs, antigomiR-625 were transfected into CECs. It was demonstrated that downregulation of miR-625 significantly increased Fas expression compared with the negative control $(\mathrm{P}<0.05 ;$ Fig. $6 \mathrm{~A})$. Meanwhile, to examine the functional role of miR- 625 on the Bcl-2 gene, pre-miR-625 and antigomiR-625 were transfected into CECs. As indicated

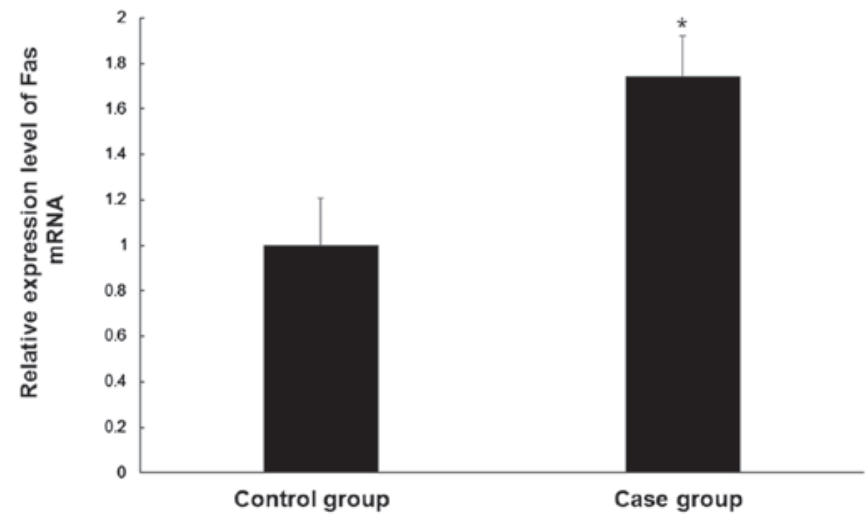

Figure 1. Comparison of Fas mRNA expression between normal cervical cartilage endplate and degenerative tissues by quantitative polymerase chain reaction. The expression of Fas mRNA was significantly higher in the case group compared with the normal control. Results are presented as the mean \pm standard deviation. ${ }^{*} \mathrm{P}<0.05$ vs. control group.

in Fig. 6B, upregulation of miR-625 increased Bcl-2 protein expression, while reducing the expression of miR-625 significantly reduced $\mathrm{Bcl}-2$ protein expression $(\mathrm{P}<0.05)$.

\section{Discussion}

CEP degeneration is directly associated with intervertebral disc degeneration. However, the exact molecular mechanism of CEP degeneration remains to be elucidated. In the present study, the role of miR-625 in CEP degeneration was examined. Fas is a transmembrane protein of the death receptor family, which can interact with FasL and induce apoptosis by activating a hierarchy of caspases (21). The Fas and FasL system constitute an important pathway mediating apoptosis in immune and tumor cells, and serve pivotal roles in numerous physiological and pathological processes, including immune homeostasis, inflammation, tumor monitoring, organ transplantation, autoimmune diseases and T- and B-lymphocyte maturation (21).

Previous reports have demonstrated that there are two major Fas-mediated mechanisms of apoptosis: One is the cell surface death receptor signaling (extracellular pathway); the other is the mitochondrial pathway (intracellular pathway) $(29,30)$. The cell surface death receptor signaling pathway is initiated on the ligand-receptor interactions at the cell surface, including the FAS-FASL system, followed by binding between receptors of the death domain and signaling molecules, and interaction with pro caspase 8 to form a death-inducing signaling complex. Subsequently caspase 3, 6 and 7 are activated, inducing cell death (31).

The Bcl-2 gene was first identified in follicular B cell lymphomas in 1985, and it was determined that it was closely associated with apoptosis (32) and was subsequently determined to be an anti-apoptotic gene. Recently, it was found that cell-death regulation proteins, including Bcl-2, Bcl-xL, Bcl-2-associated X protein and the Bcl-2 gene are capable of inhibiting apoptosis in disc cells, which is the primary mechanism of action of the Bcl-2 protein (33). In the present study, the expression of Fas was determined in degenerative and normal CEP using western blot analysis and qPCR at the protein and mRNA levels, respectively. It was observed 

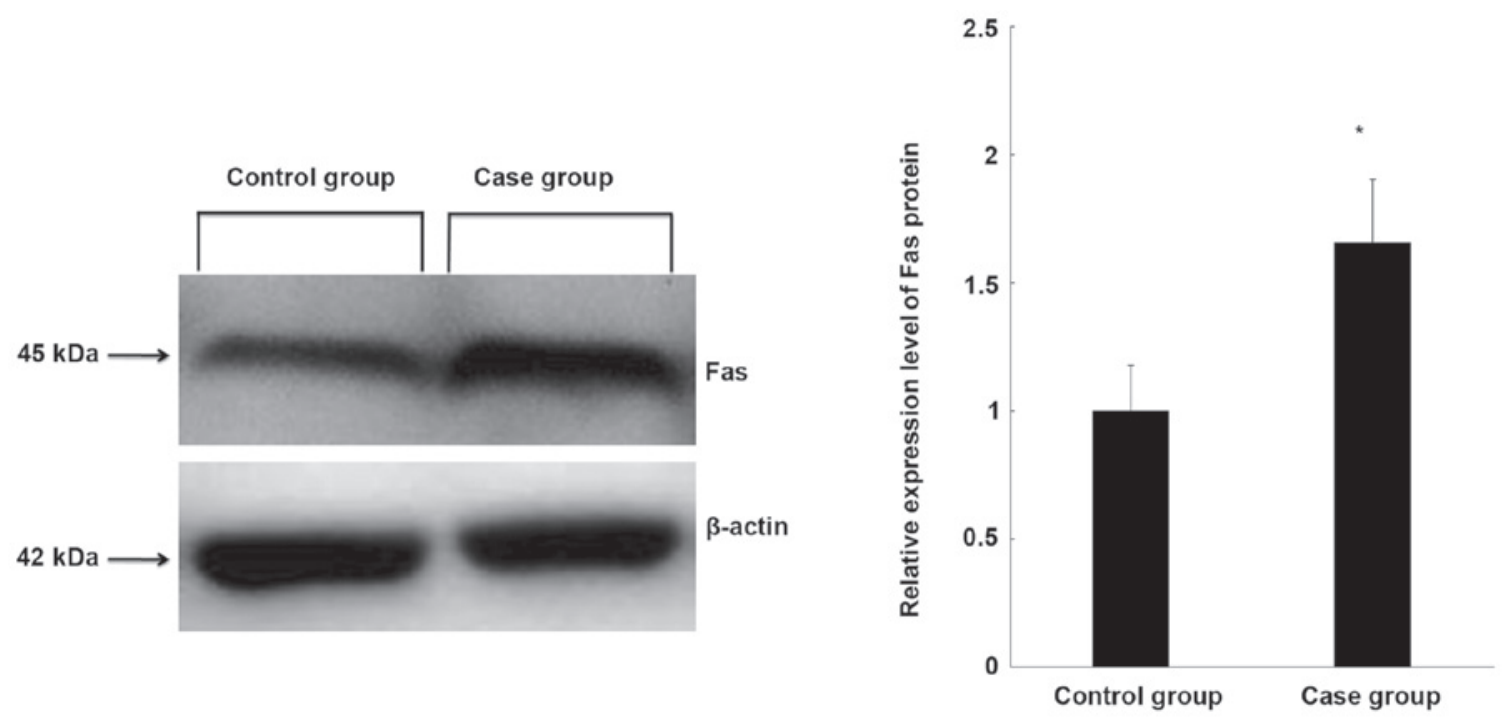

Figure 2. Comparative analyses of Fas protein levels in the tissues of normal and degenerative cervical cartilage endplate following western blot analysis. Molecular standards are indicated on the left. Quantitative analysis of blot density following normalization with that of $\beta$-actin is shown on the right hand panel. Graphical data are expressed as the mean \pm standard deviation. ${ }^{*} \mathrm{P}<0.05$ vs. control group.

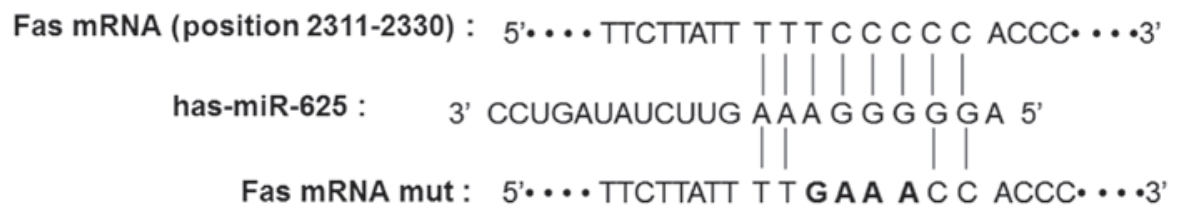

Figure 3. Complementary base pairing between miR-625 and the human Fas mRNA predicted by bioinformatics. The miR- 625 binding site is located on the 2331-2330 base pair downstream from the Fas mRNA stop codon. The 'mutated Fas mRNA sequence' base pairing is denoted by the bold letters. miR, micro RNA; mut, mutant.

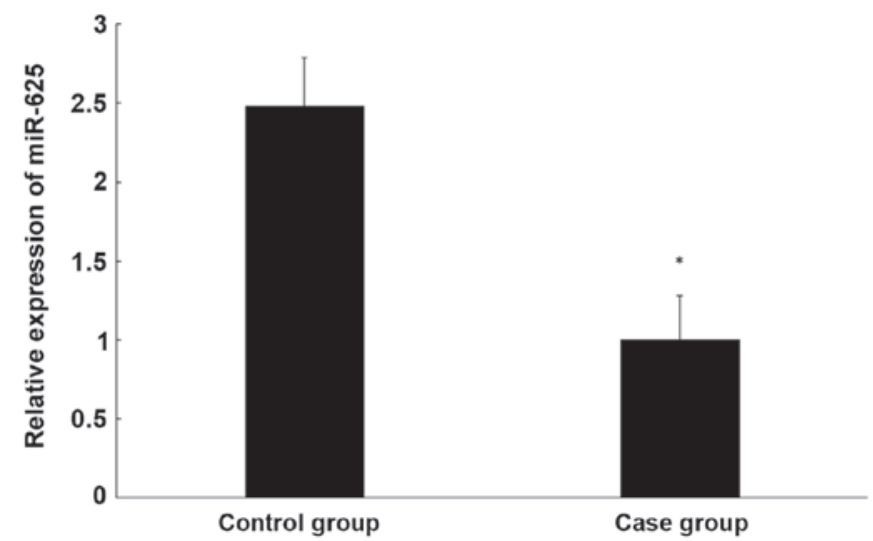

Figure 4. Differentially expressed miRNA-625 in normal and degenerative cervical cartilage endplate tissues. Bar chart describing the relative expression levels for case subgroup relative to the average expression level in normal tissues. Error bars represent the standard error. miRNA-625 in degenerative groups with highly significant differences compared with normal control. ${ }^{*} \mathrm{P}<0.05$ compared with control group. miR, micro RNA.

that expression of Fas mRNA and protein in degenerative cervical CEP tissue was higher than in the normal CEP either. A previous study by Ariga et al (10) confirmed that apoptosis of the cartilage endplate is an important pathological basis for lumbar degeneration. The results of the present study suggest that Fas-induced apoptosis of the cartilage endplate may be involved in cervical degeneration. Using a bioinformatics approach, it was predicted that miR-625 would bind to the 3'UTR of Fas through a binding domain. Therefore, the expression of miR-625 in degenerative CEP tissues was examined further and it was revealed that miR-625 expression was significantly lower in degenerative CEP compared with normal CEP, suggesting that Fas gene expression may be directly regulated by miR-625. In order to verify the regulation of Fas expression by miR-625, dual luciferase reporter gene assay was performed and this found that miR-625 can bind directly to the 3'-UTR of the Fas gene, thus inhibiting Fas protein expression. The role of abnormal expression of miRNAs in the cartilage endplate and cervical or lumbar degeneration has been studied previously; for example, Chen et al (23) reported that miR-34a regulated the apoptosis of cartilage endplate cells by targeting Bcl-2. In addition, Wang et al (34) reported that miR-155 regulated Fas-mediated apoptosis of lumbar nucleus pulposus through FADD and caspase-3. These results suggest that miRNA-mediated apoptosis may serve an important role in cervical/lumbar degeneration.

Lentiviral vector transfection experiments showed that downregulation of miR-625 in CECs can induce upregulation of Fas expression. Therefore, Bcl-2 expression was detected further and it was revealed that the upregulation of miR-625 may increase anti-apoptotic Bcl-2 expression in CECs. By contrast, downregulation of miR-625 expression can reduce Bcl-2 expression. 
A

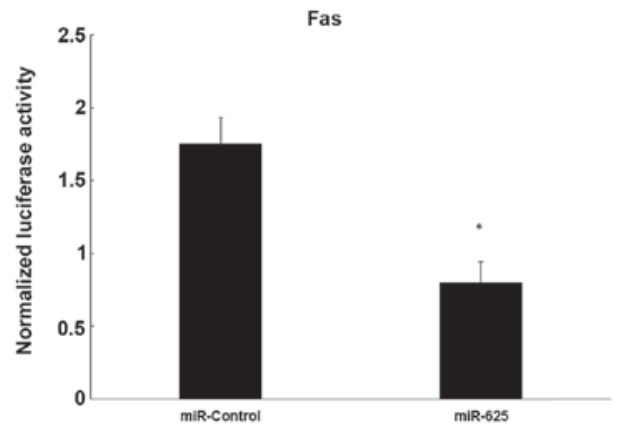

B

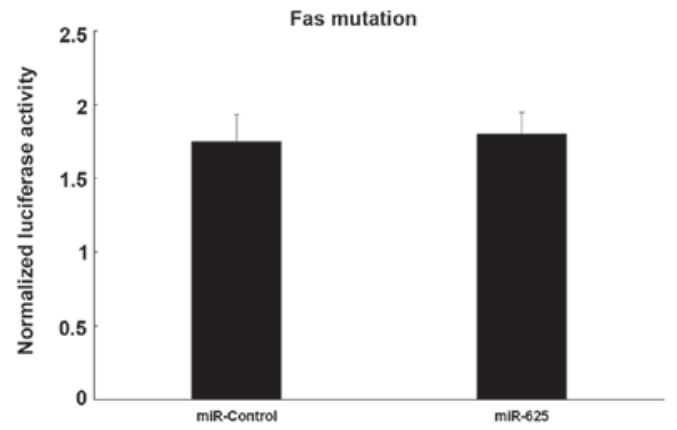

Figure 5. Luciferase assay of exosomal miRNA-625 transferred into CECs. CECs were transfected with the reporter and control plasmid for the luciferase assay. Luciferase activity was normalized with $\beta$-gal activity as shown. The mean \pm SD of triplicates was obtained. Relative luciferase activity compared with the control (CECs transfected with negative control miRNA) is presented. (A) Fas: Luciferase activity of CEC culturing with exosome pRL-TK vector and miR-625 mimics together with pFL-Fas 3'-UTR was significantly reduced compared with CECs cultured with exosomes from a negative control (n=3). (B) Mutated Fas: There was no difference in the luciferase activity between exosomes derived from pFL-Fas 3'-UTR and pRL-TK together with mimic cells and those derived from negative control cells. The mean \pm SD of replicates was obtained. "P $<0.05$ compared with miR-control. CEC, cervical cartilage endplate; SD, standard deviation; UTR, untranslated region; miR, micro RNA; pRL-TK, promoter-Renilla luciferase reporter plasmid.

A
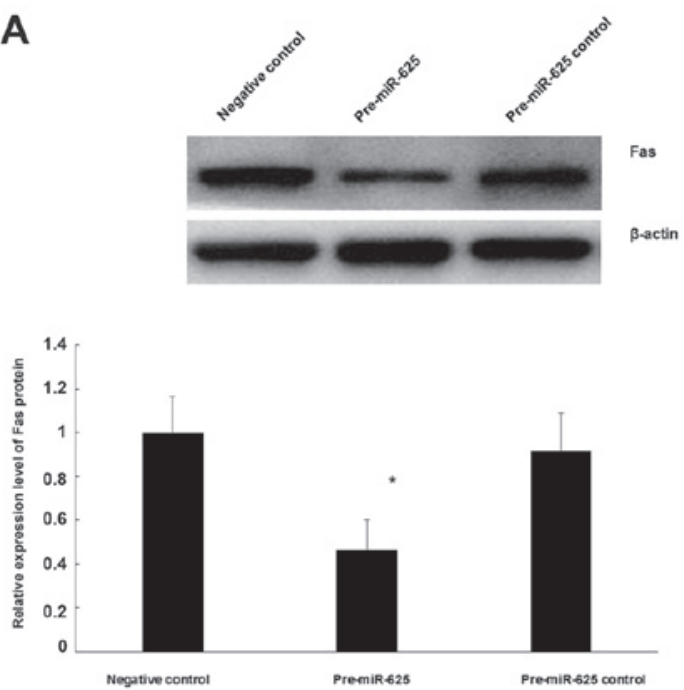

B
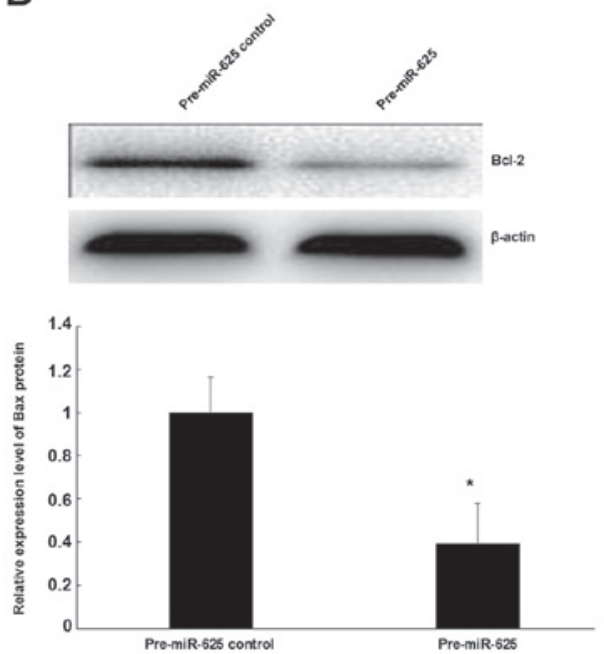
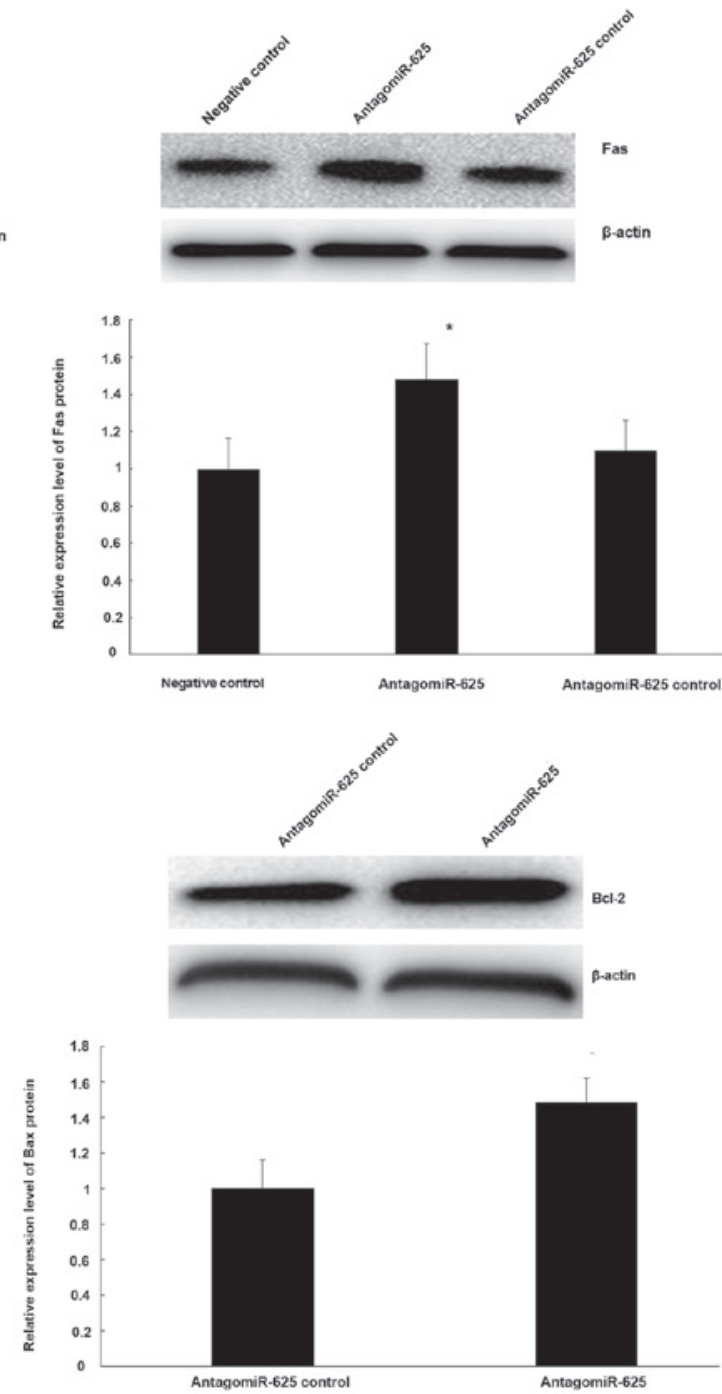

Figure 6. Analysis of Fas and Bcl-2 expression. (A) Pre-miR-625/antigomiR-625 infected CECs were examined by western blot analysis using specific antibody. Fas protein expression was inhibited by miR-625. Fas expression was reduced in cells transfected with pre-miR-625 and increased in cells transfected with antigomiR-625 compared to the negative control. " $\mathrm{P}<0.05$ compared with negative control. (B) Bcl-2 protein expression in pre-miR-625/antigomiR-625 infected CECs was detected by western blot analysis using specific antibody. The Bcl-2 protein level was significantly reduced in CECs transfected with pre-miR-625 and increased in CECs transfected with antigomiR-625. ${ }^{*} \mathrm{P}<0.05$ compared with pre-miR-625 control. Bcl-2, B-cell lymphoma 2; CEC, cervical cartilage endplate; miR, micro RNA. 
In conclusion, the results of the current study demonstrated that during degeneration of CEP, miR-625 is important in inhibiting apoptosis. This suggests that in the pathogenesis of cervical disease, downregulation of miR-625 promotes Fas-mediated cell endplate apoptosis. Therefore, miR-625 may be a novel target for the treatment of cervical disease using lentivirus-mediated pre-miR-625 expression.

\section{Acknowledgements}

The present study was supported by the Projects of Nonprofit Technology \& Research of Zhejiang Province (grant no. 2015C33294).

\section{References}

1. Irvine DH, Foster JB, Newell DJ and Klukvin BN: Prevalence of cervical spondylosis in a general practice. Lancet 1: 1089-1092, 1965.

2. Al-Ryalat NT, Saleh SA, Mahafza WS, Samara OA, Ryalat AT and Al-Hadidy AM: Myelopathy associated with age-related cervical disc herniation: A retrospective review of magnetic resonance images. Ann Saudi Med 37: 130-137, 2017.

3. Rao RD, Currier BL, Albert TJ, Bono CM, Marawar SV, Poelstra KA and Eck JC: Degenerative cervical spondylosis: Clinical syndromes, pathogenesis, and management. J Bone Joint Surg Am 89: 1360-1378, 2007.

4. Hughes SP, Freemont AJ, Hukins DW, McGregor AH and Roberts S: The pathogenesis of degeneration of the intervertebral disc and emerging therapies in the management of back pain. J Bone Joint Surg Br 94: 1298-1304, 2012.

5. Humzah MD and Soames RW: Human intervertebral disc: Structure and function. Anat Rec 220: 337-356, 1988.

6. Grunhagen T, Wilde G, Soukane DM, Shirazi-Adl SA and Urban JP: Nutrient supply and intervertebral disc metabolism. J Bone Joint Surg Am 88 (Suppl 2): S30-S35, 2006.

7. Huang YC, Urban JP and Luk KD. Intervertebral disc regeneration: Do nutrients lead the way? Nat Rev Rheumatol 10: 561-566, 2014.

8. Urban JP, Smith S and Fairbank JC: Nutrition of the intervertebral disc. Spine (Phila Pa 1976) 29: 2700-2709, 2004.

9. Moon SM, Yoder JH, Wright AC, Smith LJ, Vresilovic EJ and Elliott DM: Evaluation of intervertebral disc cartilaginous endplate structure using magnetic resonance imaging. Eur Spine J 22: 1820-1828, 2013

10. Ariga K, Miyamoto S, Nakase T, Okuda S, Meng W, Yonenobu K and Yoshikawa $\mathrm{H}$ : The relationship between apoptosis of endplate chondrocytes and aging and degeneration of the intervertebral disc. Spine (Phila Pa 1976) 26: 2414-2420, 2001.

11. Holm S, Holm AK, Ekström L, Karladani A and Hansson T: Experimental disc degeneration due to endplate injury. J Spinal Disord Tech 17: 64-71, 2004.

12. Kuss P, Kraft K, Stumm J, Ibrahim D, Vallecillo-Garcia P, Mundlos S and Stricker S: Regulation of cell polarity in the cartilage growth plate and perichondrium of metacarpal elements by HOXD13 and WNT5A. Dev Biol 385: 83-93, 2014.

13. Macsai CE, Georgiou KR, Foster BK, Zannettino AC and Xian CJ: Microarray expression analysis of genes and pathways involved in growth plate cartilage injury responses and bony repair. Bone 50: 1081-1091, 2012.

14. Pattappa G, Li Z, Peroglio M, Wismer N, Alini M and Grad S: Diversity of intervertebral disc cells: Phenotype and function. J Anat 221: 480-496, 2012.
15. Huang Y, Shen XJ, Zou Q, Wang SP, Tang SM and Zhang GZ: Biological functions of microRNAs: A review. J Physiol Biochem 67: 129-139, 2011.

16. Lim LP, Lau NC, Garrett-Engele P, Grimson A, Schelter JM, Castle J, Bartel DP, Linsley PS and Johnson JM: Microarray analysis shows that some microRNAs downregulate large numbers of target mRNAs. Nature 433: 769-773, 2005.

17. Miyaki S, Sato T, Inoue A, Otsuki S, Ito Y, Yokoyama S, Kato Y, Takemoto F, Nakasa T, Yamashita S, et al: MicroRNA-140 plays dual roles in both cartilage development and homeostasis. Genes Dev 24: 1173-1185, 2010.

18. Sumiyoshi K, Kubota S, Ohgawara T, Kawata K, Nishida T, Shimo T, Yamashiro T and Takigawa M: Identification of miR-1 as a micro RNA that supports late-stage differentiation of growth cartilage cells. Biochem Biophys Res Commun 402: 286-290, 2010.

19. Chang BS, Minn AJ, Muchmore SW, Fesik SW and Thompson CB: Identification of a novel regulatory domain in Bcl-X (L) and Bcl-2. EMBO J 16: 968-977, 1997.

20. Yabuki S, Onda A, Kikuchi S and Myers RR: Prevention of compartment syndrome in dorsal root ganglia caused by exposure to nucleus pulposus. Spine (Phila Pa 1976) 26: 870-875, 2001.

21. Nagata S and Golstein P: The Fas death factor. Science 267: 1449-1456, 1995

22. Blanco FJ, Guitian R, Vazquez-Martul E, de Toro FJ and Galdo F: Osteoarthritis chondrocytes die by apoptosis. A possible pathway for osteoarthritis pathology. Arthritis Rheum 41: 284-289, 1998.

23. Chen H, Wang J, Hu B, Wu X, Chen Y, Li R and Yuan W: MiR-34a promotes Fas-mediated cartilage endplate chondrocyte apoptosis by targeting Bcl-2. Mol Cell Biochem 406: 21-30, 2015.

24. Xu YQ, Zhang ZH, Zheng YF and Feng SQ: Dysregulated miR-133a mediates loss of type II collagen by directly targeting matrix metalloproteinase 9 (MMP9) in human intervertebral disc degeneration. Spine (Phila Pa 1976) 41: E717-E724, 2016.

25. Wang C, Wang WJ, Yan YG, Xiang YX, Zhang J, Tang ZH and Jiang ZS: MicroRNAs: New players in intervertebral disc degeneration. Clin Chim Acta 450: 333-341, 2015.

26. Kuisma M, Karppinen J, Haapea M, Lammentausta E, Niinimäki J and Tervonen O: Modic changes in vertebral endplates: A comparison of MR imaging and multislice CT. Skeletal Radiol 38: 141-147, 2009.

27. Chomczynski P and Sacchi N: Single-step method of RNA isolation by acid guanidinium thiocyanate-phenol-chloroform extraction. Anal Biochem 162: 156-159, 1987.

28. Livak KJ and Schmittgen TD: Analysis of relative gene expression data using real-time quantitative PCR and the 2(-Delta Delta C(T)) method. Methods 25: 402-408, 2001.

29. Nagata S: Apoptosis by death factor. Cell 88: 355-365, 1997.

30. Wang X: The expanding role of mitochondria in apoptosis. Genes Dev 15: 2922-2933, 2001.

31. Nagata S: Fas ligand-induced apoptosis. Annu Rev Genet 33: 29-55, 1999.

32. Tsujimoto Y, Cossman J, Jaffe E and Croce CM: Involvement of the bcl-2 gene in human follicular lymphoma. Science 228: 1440-1443, 1985

33. Scaffidi C, Fulda S, Srinivasan A, Friesen C, Li F, Tomaselli KJ, Debatin KM, Krammer PH and Peter ME: Two CD95 (APO-1/Fas) signaling pathways. EMBO J 17: 1675-1687, 1998.

34. Wang HQ, Yu XD, Liu ZH, Cheng X, Samartzis D, Jia LT, Wu SX, Huang J, Chen J and Luo ZJ: Deregulated miR-155 promotes Fas-mediated apoptosis in human intervertebral disc degeneration by targeting FADD and caspase-3. J Patho 225: 232-242, 2011. 